\title{
O gênero Campomanesia (Myrtaceae) no estado do Paraná, Brasil
}

\author{
The genus Campomanesia (Myrtaceae) in the state of Paraná, Brazil
}

\author{
Duane Fernandes Lima ${ }^{1}$, Renato Goldenberg ${ }^{2}$ \& Marcos Sobral ${ }^{3}$
}

\begin{abstract}
Resumo
O gênero Campomanesia Ruiz \& Pav. pode ser reconhecido pelo ovário 4-18-locular, com vários óvulos por lóculo, e parede locular glandular nos frutos maduros, que serve como um falso envoltório das sementes. Normalmente todos ou todos menos um óvulo abortam em cada lóculo. Apresenta pedúnculos unifloros, dicásios ou racemos, e os botões têm cálice desde aberto até completamente fechado. No estado do Paraná, o gênero apresenta 11 espécies (C. adamantium, C. aurea, C. eugenioides, C. guaviroba, C. guazumifolia, C. neriiflora, C. pubescens, C. reitziana, C. schlechtendaliana, C. sessiliflora, C. xanthocarpa), distribuídas por todos os tipos de vegetação. Campomanesia neriiflora teve seus frutos descritos pela primeira vez. Neste trabalho são apresentadas chave de identificação, descrições, ilustrações, dados sobre distribuição geográfica e lista de materiais selecionados para as espécies de Campomanesia do Paraná.
\end{abstract}

Palavras-chave: Brasil, flora, Myrteae, taxonomia.

\begin{abstract}
The genus Campomanesia Ruiz \& Pav. can be recognized by the ovary 4-18-locular, with several ovules per locule, and a glandular locular wall in the mature fruits, which serves as a false seed coat. Usually all or all but one ovule abort in each locule. The inflorescence is uniflorous, dichasium or raceme, and the calyx can be opened or completely closed in the flower bud. The genus has 11 species in the state of Paraná (C. adamantium, C. aurea, C. eugenioides, C. guaviroba, C. guazumifolia, C. neriiflora, C. pubescens, C. reitziana, C. schlechtendaliana, C. sessiliflora, C. xanthocarpa), distributed in all vegetation types. Campomanesia neriiflora had your fruits described for the first time. In this work we present an identification key, descriptions, illustrations, data on geographic distribution and collection lists for the species of Campomanesia from Paraná.
\end{abstract}

Key words: Brazil, flora, Myrteae, taxonomy.

\section{Introdução}

Myrtaceae apresenta pelo menos 132 gêneros e mais de 5600 espécies (Govaerts et al. 2008). A família era tradicionalmente dividida em duas subfamílias: Leptospermoideae, predominante na Oceania e caracterizada pelos frutos secos, e Myrtoideae, com frutos carnosos, de distribuição pantropical e centro de irradiação na América do Sul (Legrand \& Klein 1978; Sobral 2003). Entretanto, estudos filogenéticos recentes mostraram que os caracteres usados para a distinção entre as duas subfamílias não são consistentes (Wilson et al. 2001, 2005), e que caracteres como frutos secos ou carnosos surgiram independentemente em diversas linhagens da família.
Wilson et al. (2005) propõem uma reorganização da família, com duas novas subfamílias: Psiloxyloideae e Myrtoideae. Psiloxyloideae é definida, entre outros caracteres, pela presença de flores unissexuadas, óvulos com saco embrionário bispórico e número cromossômico básico $\mathrm{x}=12$, e compreende dois gêneros africanos, Psiloxylon Thouars ex Tul. e Heteropyxis Harv., enquanto Myrtoideae, definida por flores bissexuadas, óvulos com saco embrionário monospórico e número cromossômico básico $\mathrm{x}=11$, compreende todos os demais gêneros. Dentro da subfamília Myrtoideae há 15 tribos (Wilson et al. 2005), dentre as quais a tribo Myrteae, que compreende todas as Myrtaceae americanas, à

'Curso de Ciências Biológicas/UFPR, bolsista CNPq. Autor para correspondência: duaneflima@gmail.com

${ }^{2}$ UFPR, SCB, Depto. Botânica,. C.P. 19031, 81531-970, Curitiba, PR. rgolden@ufpr.br bolsista CNPq

${ }^{3}$ UFSJ, Depto. Ciências Naturais,. 36301-160, São João del-Rei, MG. marcos_sobral@hotmail.com 
exceção do gênero andino monotípico Tepualia Griseb., e é encontrada em regiões tropicais, subtropicais e marítimas (Landrum 1986).

Tradicionalmente, Campomanesia Ruiz \& Pav. pertence à subtribo Myrtinae, com hipocótilo desenvolvido e cotilédones pequenos ou vestigiais (McVaugh 1968). Atualmente, dados moleculares (Lucas et al. 2007) mostram que Myrtinae não é um grupo monofilético, e os autores propõem uma classificação baseada em grupos informais. Dessa forma, o gênero é incluído no grupo em torno do gênero Pimenta Lindl., com embrião em forma de C, cotilédones carnosos não completamente fusionados, testa óssea ou membranácea, e placas escalariformes ausentes.

Campomanesia tem 36 espécies conhecidas (Govaerts et al. 2008), com 31 delas na flora brasileira (Sobral et al. 2010). São árvores e arbustos, distribuídos do nordeste da Argentina até Trinidad, e da costa do Brasil até os Andes no Peru, Equador e Colômbia (Landrum 1982). O gênero pode ser reconhecido pelo ovário 4-18-locular, com vários óvulos por lóculo, pelo não desenvolvimento de óvulos, ou de apenas um, ou raramente dois em cada lóculo, e pelas paredes dos lóculos glandulares nos frutos maduros, servindo como um falso envoltório das sementes, que apresentam testa membranácea. As inflorescências são unifloras, dicásios ou racemos, e as flores apresentam cálice aberto até completamente fechado, abrindo-se em lobos irregulares (Landrum 1982; Landrum \& Kawasaki 1997).

A última revisão completa do gênero foi realizada por Landrum (1986), que mencionou dez espécies para o estado do Paraná. Para os demais estados do Sul do Brasil, foram feitos estudos em Santa Catarina (Legrand \& Klein 1977) e no Rio Grande do Sul (Sobral 2003). Tendo em vista a vasta ocorrência de espécies de Campomanesia por todo Paraná, este trabalho tem por objetivo fornecer subsídios para futuros estudos relacionados com a Flora do Paraná. Aqui serão apresentadas as descrições das espécies ocorrentes no estado, bem como suas distribuições geográficas, dados de floração e frutificação, chave para identificação das espécies e ilustrações.

\section{Material e Métodos}

O presente trabalho foi realizado através da análise de exsicatas depositadas nos herbários paranaenses EFC, HUEM, HUPG, MBM e UPCB (Thiers 2010). Apenas coletas provenientes do estado do Paraná foram listadas como "material selecionado" em cada espécie, e apenas uma exsicata por município foi citada, exceto quando a espécie apresenta distribuição muito restrita. Quando preciso, por falta de coletas provenientes do estado, coletas de estados ou países vizinhos foram analisadas e listadas como "material adicional". Tanto os dados de floração e frutificação quanto as distribuições geográficas regionais foram descritas com base nas coleções dos herbários visitados.

As espécies estão dispostas em ordem alfabética. Táxons infra-específicos não foram considerados nesse trabalho, por não mostrarem separações consistentes. Para listagem de sinonímias, ver Landrum (1986).

O Paraná está localizado na Região Sul do Brasil, entre as latitudes $22^{\circ} 29^{\prime} 30^{\prime \prime} \mathrm{e} 26^{\circ} 42^{\prime} 59^{\prime \prime}$ Sul, e longitudes $48^{\circ} 02^{\prime} 24^{\prime \prime}$ e $54^{\circ} 37^{\prime} 38^{\prime \prime}$ 'Oeste, ocupando uma área de $199.314 \mathrm{~km}^{2}$. Limita-se ao norte com estado de São Paulo, a leste com o Oceano Atlântico, ao sul com o estado de Santa Catarina e a oeste com o estado do Mato Grosso do Sul, e os países Paraguai e Argentina.

No estado são conhecidas cinco zonas de paisagens naturais, que se sucedem de leste para o oeste: Litoral, Serra do Mar, Primeiro Planalto ou de Curitiba, Segundo Planalto ou de Ponta Grossa, e Terceiro Planalto ou de Guarapuava (Maack 1968). Cinco tipos de vegetação são conhecidos no Paraná (Leite 1994): (1) floresta ombrófila densa predominante no Litoral e na Serra do Mar, com os subtipos altomontana (acima de $1000 \mathrm{~m}$ ), montana (400-1000 m), submontana (30-400 m), e de terras baixas $(0-30 \mathrm{~m})$, além de outras formações pioneiras, como restingas, manguezais e campos de altitude; (2) floresta ombrófila mista, predominante nas regiões planaltinas mais altas do centro e sul do estado; (3) floresta estacional semidecidual, predominantes no norte e oeste do segundo e terceiro planaltos; (4) estepe ombrófila, ou campos gerais, predominante principalmente no planalto de Ponta Grossa; (5) savana estacional, ou cerrado, com manchas isoladas no nordeste do estado.

\section{Resultados e Discussão}

Campomanesia Ruiz \& Pav., Fl. Peruv. Prodr.72, tab.13.1794.

Subarbustos a árvores glabros ou com indumento simples. Folhas opostas, pecioladas, broquidódromas, sem nervura marginal distinta. Inflorescências reduzidas a uma única flor ou dicásios 
trifloros, axilares ou sobre ramos novos; bractéolas decíduas antes ou após antese. Flores 5-meras; lobos do cálice verdes, desde abertos até completamente fusionados, abrindo-se irregularmente, persistentes nos frutos; pétalas brancas, obovais; estames com deiscência longitudinal; ovário ínfero, 4-13-locular, vários óvulos por lóculo, arranjados em duas fileiras com placentação axilar; estiletes glabros ou com tricomas na base; estigma capitado. Frutos plurisseminados, globosos, esverdeados, amarelos ou alaranjados, cálice persistente. Embrião mirtóide, com falsa testa glandular.

\section{Chave de identificação para as espécies de Campomanesia no Paraná}

1. Botão floral abrindo-se em lobos irregulares, com cálice totalmente fechado ou quase fechado, com uma abertura no ápice.

2. Botão floral com cálice completamente fechado

5. C. guazumifolia

2'. Botão floral com cálice quase fechado, com abertura no ápice 9. C. schlechtendaliana

1'. Botão floral com lobos individualizados e com cálice totalmente aberto.

3. Folhas sem domácias formadas por tufos de tricomas nas axilas das nervuras secundárias na face abaxial.

4. Folhas densamente cobertas por tricomas em ambas as faces ..... 7. C. pubescens

4'. Folhas glabras ou esparsamente cobertas por tricomas, ou com apenas as nervuras densamente cobertas por tricomas.

5. Pedúnculos 0,1-1,5 cm compr. Ramos e apenas as nervuras das folhas densamente cobertos por tricomas 10. C. sessiliflora

5'. Pedúnculos 1,5-4 cm compr. Ramos e folhas com superfície e nervuras glabras ou esparsamente cobertos por tricomas.

6. Folhas com ápice abruptamente acuminado, face adaxial lustrosa .... 3. C. eugenioides

6. Folhas com ápice de agudo a arredondado, face adaxial não lustrosa.

7. Glândula apical frequentemente presente nos estames. Folhas, lobos do cálice e pétalas densamente cobertos por glândulas 2. C. aurea

7'. Glândula apical ausente nos estames. Folhas, lobos do cálice e pétalas esparsamente cobertos por glândulas 1. C. adamantium

3'. Folhas com domácias formadas por tufos de tricomas nas axilas das nervuras secundárias na face abaxial.

8. Folhas com margem denticulata, lâmina frequentemente bulada 8. C. reitziana 8. Folhas com margem inteira ou crenada, lâmina sempre lisa.

9. Pétalas 20-30 $\times 18-25 \mathrm{~mm}$. Estilete $11-17 \mathrm{~mm}$ compr. Frutos enrugados .... 6. C. neriiflora

9'. Pétalas 4-12 $\times 2,5-11 \mathrm{~mm}$. Estilete $2-7 \mathrm{~mm}$ compr. Frutos lisos.

10. Lobos do cálice $0,7-1,8$ vezes mais compridos que largos. Ramos e pedúnculos glabros ou com tricomas esparsos 11. C. xanthocarpa

10'. Lobos do cálice 0,4-0,7 vezes mais compridos que largos. Ramos e pedúnculos de moderadamente a densamente cobertos por tricomas 4. C. guaviroba

1.Campomanesia adamantium (Cambess.) O.Berg, Linnaea 27(4): 434. 1856. Fig. 1a-1

Pequenas árvores ou arbustos $0,5-2 \mathrm{~m}$ alt.; ramos, pecíolos, pedúnculos e folhas glabros, raro esparsamente cobertos por tricomas $0,1-0,3 \mathrm{~mm}$ compr. Folhas com pecíolo 1-8 mm compr.; lâmina 2,5-7×7,5-4,5 cm, elíptica, oblonga, lanceolada ou oboval, discolor, não lustrosa, plana, cartácea a coriácea, ápice de agudo a atenuado, base aguda ou obtusa, margem inteira, nervuras laterais $5-10$ de cada lado, todas as nervuras salientes na face abaxial e impressas ou sulcadas na face adaxial, sem domácias formadas por tufos de tricomas na face abaxial, glândulas esparsas em ambas as faces. Pedúnculos 1,5-3,7 cm comp., unifloros; bractéolas $1-6 \times 0,1-0,7 \mathrm{~mm}$, lineares ou lanceoladas, caducas após antese. Flores com hipanto glabro; cálice aberto no botão, com lobos 2-4×2-4 mm, 0,5-1,5 vezes mais compridos que largos, cobertos por tricomas internamente ou nas margens, glândulas presentes externamente; pétalas 6,5-9,5 × 3,5$7,5 \mathrm{~mm}$, glabras ou com tricomas nas margens, glândulas presentes externamente; estames 80-120, glândula apical ausente; ovário 5-9-locular; estilete 4-8 mm compr. Fruto 5,5-10×4,5-10 mm, globoso, liso, glabro. 

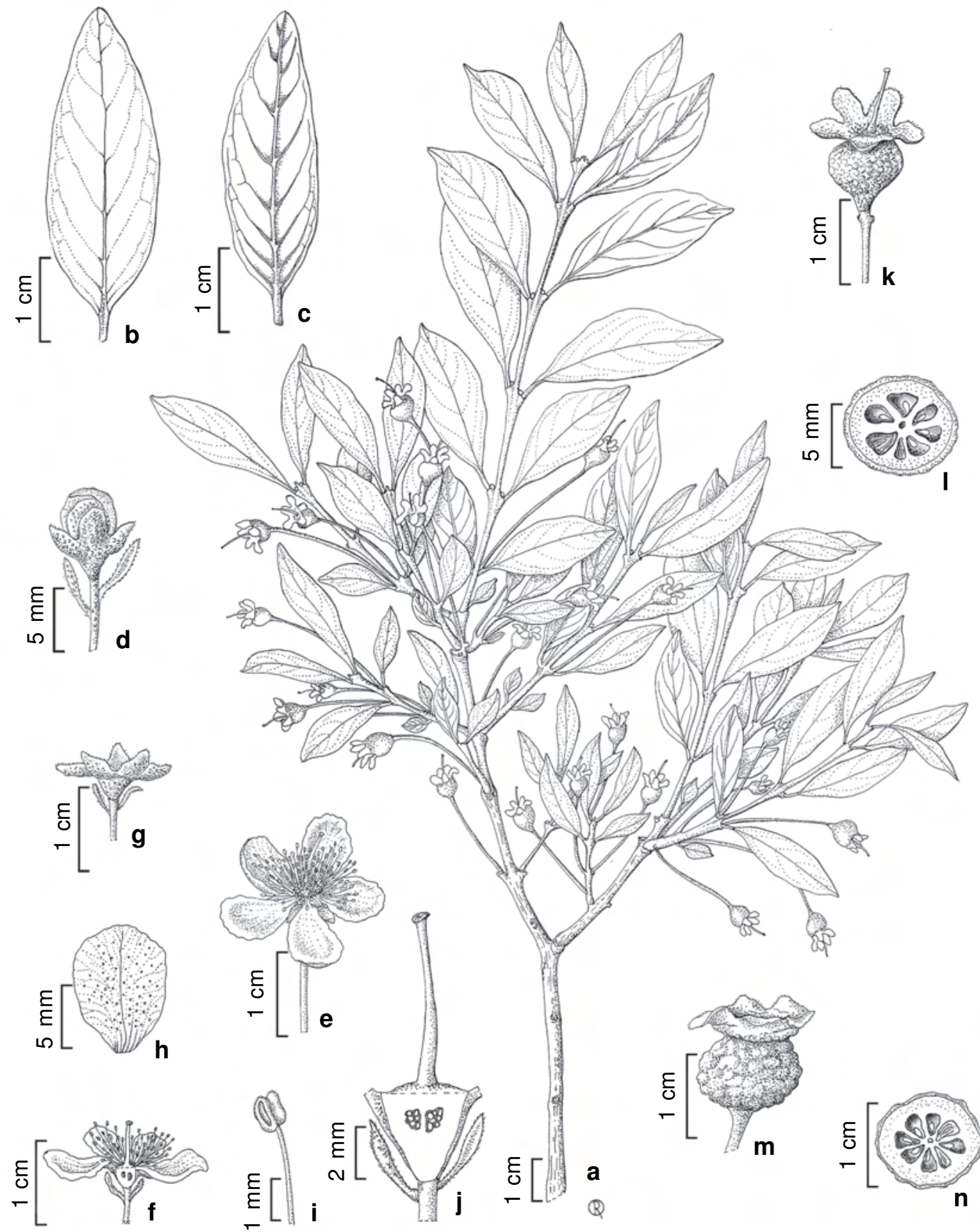

Figura 1 - a-1. Campomanesia adamantium - a. ramo com frutos jovens (Lima 64); b. face adaxial da folha (Lima 64); c. face abaxial da folha (Lima 64); d. botão floral com bractéolas (Lima 66); e. flor em antese (Lima 66); f. flor em antese em corte longitudinal (Lima 66); g. detalhe dos lobos do cálice, hipanto e bractéolas (Lima 66); h. pétala (Lima 66); i. estame (Lima 66); j. detalhe do ovário em corte longitudinal, evidenciando os lóculos e óvulos (Lima 66); k. fruto imaturo (Lima 64); 1. corte transversal de fruto imaturo, evidenciando vários lóculos (Lima 64). m-n. C. neriiflora (Isernhagen 231) $\mathrm{m}$. fruto maduro; $\mathrm{n}$. corte transversal de fruto maduro, evidenciando vários lóculos.

Figure 1 - a-l. Campomanesia adamantium - a. branch with immature fruits (Lima 64); b. abaxial surface of the leaf(Lima 64); c. adaxial surface of the leaf (Lima 64); d. flower bud with bracteoles (Lima 66); e. flower at anthesis (Lima 66); f. longitudinal section of the flower at anthesis (Lima 66); g. detail of the calyx, hypanthium and brateoles (Lima 66); h. petal (Lima 66); i. stamen (Lima 66); j. detail of the ovary in longitudinal section, showing the locules and ovules (Lima 66); k. immature fruit (Lima 64); 1. transversal section of immature fruit, showing several locules (Lima 64). m-n. C. neriiflora (Isernhagen 231) - m. mature fruit; $n$. Transversal section of the mature fruit, showing several locules. 


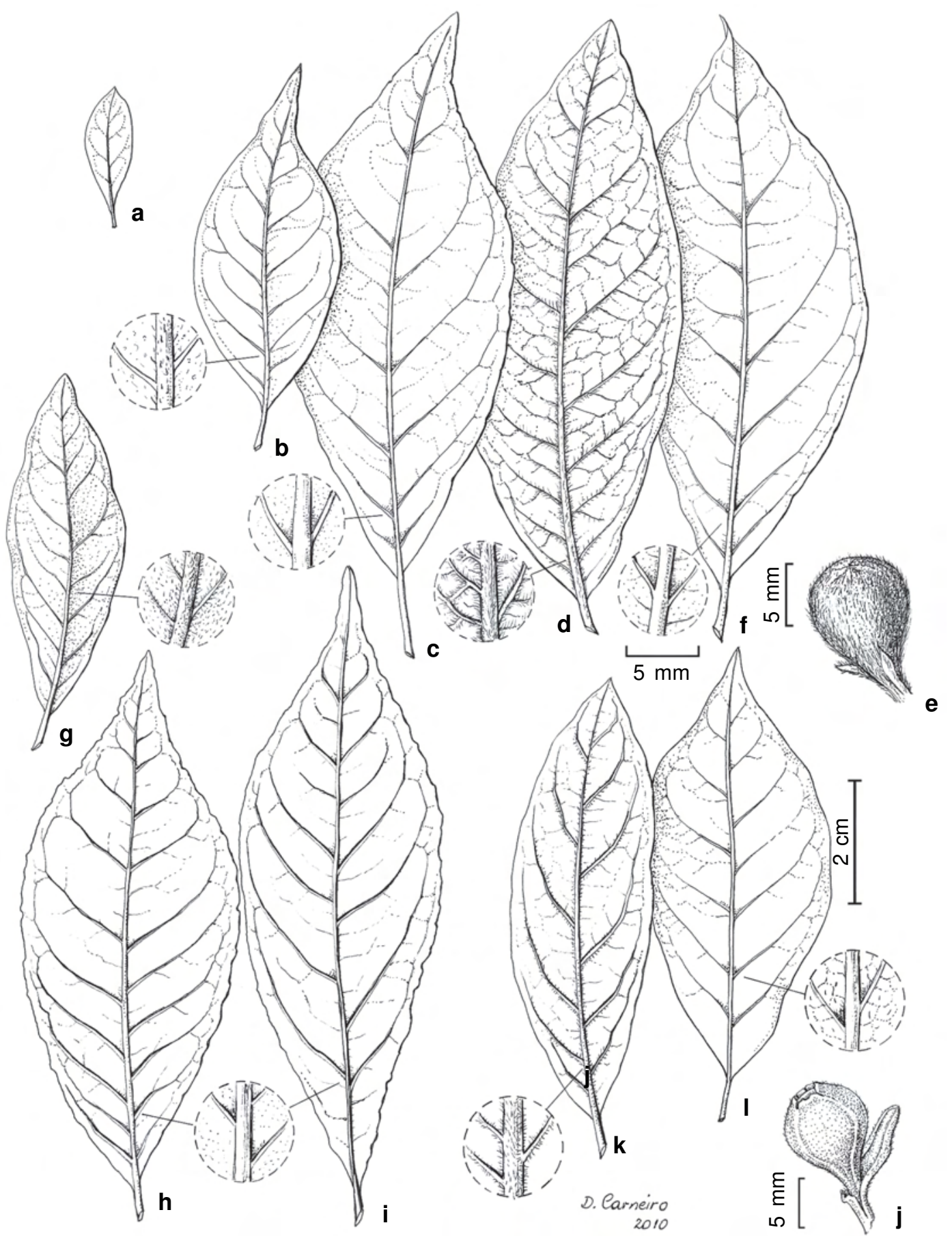

Figura 2 - a-d, f-i, k-1 - Folhas de espécies de Campomanesia do Paraná (face abaxial). e, j - Botões florais. - a. C. aurea (Silva 1000). b. C. eugenioides (Hatschbach 40337). c. C. guaviroba (Lacerda 129). d. C. guazumifolia (Hatschbach 35427). e. C. guazumifolia (Paiva UPCB 36131). f. C. neriiflora (Silva 4395). g. C. pubescens (Hatschbach 22576). h. C. reitziana (Silva 1648). i. C. schlechtendaliana (Hatschbach 44467). j. C. schlechtendaliana (Hatschbach 5213). k. C. sessiliflora (Caxambu 200). 1. C. xanthocarpa (Britez 978).

Figure 2 - a-d, f-i, k-1 - Leaves of species of Campomanesia from Paraná (abaxial surface). e, j-Flower buds. - a. C. aurea (Silva 1000). b. C. eugenioides (Hatschbach 40337). c. C. guaviroba (Lacerda 129). d. C. guazumifolia (Hatschbach 35427). e. C. guazumifolia (Paiva UPCB 36131). f. C. neriiflora (Silva 4395). g. C. pubescens (Hatschbach 22576). h. C. reitziana (Silva 1648). i. C. schlechtendaliana (Hatschbach 44467). j. C. schlechtendaliana (Hatschbach 5213). k. C. sessiliflora (Caxambu 200). 1. C. xanthocarpa (Britez 978). 
Material selecionado: Almirante Tamandaré, 11.X.1961, fl., G. Hatschbach 8457 (MBM, UPCB). Balsa Nova, 21.X.2006, fl., C. Kozera 3311 (EFC, UPCB). Campo Mourão, 11.IX.2004, fr., E.A. Maieski 41 (UPCB). Curitiba, 9.X.1989, fl., F. França (UPCB 36282). Guarapuava, 19.X.1962, fl., G. Hatschbach 9320 (MBM, UPCB). Palmeira, 3.XI.1981, fl., G. Hatschbach 44453 (MBM, UPCB). Ponta Grossa, 10.IX.2010, fl., D.F. Lima 64(UPCB); 10.IX.2010, fr., D.F. Lima 66 (UPCB). Rio Branco do Sul, 13.IX.2001, fl., J.M. Silva 3444 (FUEL, UPCB). Telêmaco Borba, 7.X.1986, fl., G. Hatschbach 30611 (MBM).

Espécie ocorre no Paraguai e Brasil, de Santa Catarina a Mato Grosso, Goiás e Minas Gerais (Landrum 1986; Sobral et al. 2010). No Paraná, ocorre em estepe, savana, e áreas abertas em domínio de floresta ombrófila mista e floresta estacional semidecidual. Coletada com flores de agosto a abril, e frutos de setembro a maio.

A espécie é caracterizada por ser um arbusto com folhas inteiramente glabras, glândulas esparsas bem evidentes, podendo apresentar alguns tricomas nas margens. Os pedúnculos podem estar nas axilas de folhas normais, folhas menores ou brácteas. Alguns espécimes podem ser confundidos com $C$. aurea, e diferem destas por apresentar folhas menos densamente cobertas por glândulas.

2. Campomanesia aurea O.Berg in Mart., Fl. Bras. 14(1): 454.1857.

Fig. 2a

Arbustos ou subarbustos 0,5-1 m alt.; ramos, pecíolos, pedúnculos e folhas glabros, raro esparsamente cobertos por tricomas $0,1-0,3 \mathrm{~mm}$ compr. Folhas com pecíolo 0,5-3,5 mm compr.; lâmina 0,9-5,5×0,3-2 cm, elíptica, oboval, oblonga ou lanceolada, discolor, não lustrosa, plana, coriácea, raro cartácea, ápice agudo a arredondado, base aguda a arredondada, margem inteira, nervuras laterais 5-8 de cada lado, todas as nervuras salientes ou impressas na face abaxial e impressas na face adaxial, sem domácias formadas por tufos de tricomas na face abaxial, densamente coberta por glândulas em ambas as faces. Pedúnculos 1,6-3 cm compr., unifloros; bractéolas 1,5-4,5 ×0,1-1 mm, lineares, caducas após antese. Flores com hipanto glabro; cálice aberto no botão, com lobos 1-3,5 × 1-3,5 mm, 0,4-1,4 vezes mais compridos que largos, cobertos por tricomas internamente ou nas margens, densamente cobertos por glândulas externamente; pétalas 4,5-11 × 2,5-9,5 mm, glabras ou com tricomas interiormente ou nas margens, densamente coberta por glândulas externamente; estames 70170, glândula apical frequentemente presente; ovário 4-8-locular; estilete 3-6 mm compr. Fruto 4$8 \times 4-8 \mathrm{~mm}$, globoso, liso, glabro.
Material selecionado: Balsa Nova, 13.XII.1979, fr., G. Hatschbach 42625 (MBM). Campo Largo, 12.X.1961, fl., G. Hatschbach 8326 (MBM, UPCB). Clevelândia, 21.XI.1971, fl., G. Hatschbach 30798 (MBM). Curitiba, 17.II.1992, fr., J.M. Silva 1000 (MBM). Guarapuava, 14.XII.1973, fl., G. Hatschbach 33531(MBM). Palmas, 4.XII.1971, fl., G. Hatschbach 28163 (MBM). Palmeira, 2.XII.1981, fr., L.R. Landrum 3949 (MBM). Ponta Grossa, 21.X.1995, fl., C.B. Poliquesi 449 (MBM). Tibagi, 3.XI.1994, fr., L.H. Soares-Silva 299 (EFC, FUEL).

Espécie ocorre no Paraguai, Argentina, Uruguai e Brasil, do Rio Grande do Sul ao Paraná (Landrum 1986; Sobral et al. 2010). No Paraná, ocorre em estepe e áreas abertas em domínio de floresta ombrófila mista. Coletada com flores de setembro a dezembro, e frutos de outubro a dezembro.

Campomanesia aurea é um arbusto inteiramente glabro, com folhas, lobos do cálice e pétalas densamente glandulares. Suas flores e folhas geralmente são pequenas quando comparadas às outras espécies de Campomanesia ocorrentes no estado. O Paraná é limite norte brasileiro da espécie.

3. Campomanesia eugenioides (Cambess.) D.Legrand, Notul. Syst. 15(3): 274. 1958. Fig. 2b Árvores 3-8 m alt.; ramos, pecíolos, pedúnculos e folhas esparsamente cobertos por tricomas $0,1-0,3 \mathrm{~mm}$ compr., raro glabros. Folhas com pecíolo 1-7 mm compr.; lâminas 1,5-5,5×0,8$3 \mathrm{~cm}$, elíptica a oval, raro lanceolada, discolor, face adaxial lustrosa, plana, cartácea ou coriácea, ápice abruptamente acuminado, base atenuada a arredondada, margem inteira, nervuras laterais 6-8 de cada lado, todas as nervuras salientes na face abaxial e impressas na face adaxial, sem domácias formadas por tufos de tricomas na face abaxial, glândulas em ambas as faces. Pedúnculos 1,5-2,5 cm compr., unifloros; bractéolas não vistas, caducas antes da antese. Flores com hipanto glabro; cálice aberto no botão, com lobos 1-1,5 × 1,5-2,5 mm, $0,6-0,9$ vezes mais compridos que largos, cobertos por tricomas internamente e nas margens, glândulas presentes externamente; pétalas 6-6,5 ×2,5-4 mm, tricomas nas margens, glândulas presentes externamente; estames 70-150, glândula apical ausente; ovário 5-6-locular; estilete 5-6 mm compr. Frutos 5,5-6,5 ×5,5-7 mm, globoso, liso, glabro. Material selecionado: Cerro Azul, 5.X.1977, fl., G. Hatschbach 40337 (MBM). Curiúva, 9.XII.1995, fr., L.H. Soares-Silva 571 (FUEL, MBM). Imbituva, 20.X.1969, fl., G. Hatschbach 22512 (MBM). Ortigueira, 8.XI.2000, fr., J.A. Ferreira (FUEL, MBM 338078). Prudentópolis, 12.XI.1985, fl., R. Kummrow 2655 (MBM). 
Espécie ocorre no Brasil, de Santa Catarina ao Mato Grosso, Goiás e Pernambuco (Landrum 1986; Sobral et al. 2010). No Paraná, ocorre em floresta ombrófila mista e floresta estacional semidecidual. Coletada com flores de setembro a novembro, e frutos de outubro a dezembro.

No estado, a espécie é caracterizada por suas folhas frequentemente ovais, densamente glandulares, com ápice abruptamente acuminado, e face adaxial lustrosa. Os lobos do cálice são mais largos que longos. No botão floral, o globo petalífero é bem evidente.

\section{Campomanesia guaviroba (DC.) Kiaersk.,} Enum. Myrt. Bras. 8. 1893.

Fig. 2c

Árvores 5-18m alt.; ramos, pecíolos e pedúnculos de moderadamente a densamente coberto por tricomas $0,1-0,3 \mathrm{~mm}$ comp. Folhas com pecíolos 2-14 mm compr.; lâmina 3-12,5 × 1-5 cm, elíptica, raro lanceolada ou oval, discolor, não lustrosa, plana, membranácea a coriácea, ápice acuminado ou agudo, base aguda ou obtusa, raro arredondada, margem inteira, menos frequentemente crenada, nervuras laterais $5-10$ de cada lado, todas as nervuras salientes na face abaxial e impressas ou sulcadas na face adaxial, ambas as faces glabras ou com tricomas esparsos sobre toda a superfície ou apenas sobre as nervuras, face abaxial sempre com domácias formadas por tufos de tricomas nas axilas das nervuras secundárias, glândulas em ambas as faces. Pedúnculos 1-5 cm compr., unifloros; bractéolas $1-2 \times 0,5-0,6 \mathrm{~mm}$, lineares, caducas antes da antese. Flores com hipanto de moderadamente a densamente coberto por tricomas; cálice aberto no botão, com lobos $1-2 \times 2-3,3 \mathrm{~mm}, 0,4-0,7$ vezes mais compridos que largos, tricomas presentes em ambas as faces, glândulas presentes externamente; pétalas 4-12 ×3-11 mm, glabras ou com tricomas externamente ou nas margens, glândulas presentes externamente; estames 150-400, glândula apical presente ou ausente; ovário 8-10(-12)-locular; estilete $2-5 \mathrm{~mm}$ compr. Fruto $10-20 \times 10-20 \mathrm{~mm}$, globoso, liso, tricomas presentes.

Material selecionado: Amaporã, 13.V.1988, fl., S. Goetzeke 344 (UPCB). Antonina, 13.V.1989, fr., G. Hatschbach 52760 (MBM, UPCB). Araucária, 2.XI.2001, fl., M.L. Bardal 76 (MBM). Campina Grande do Sul, 29.XI.1962, fl., E. Moreira 407 (UPCB). Castro, 6.XI.1966, F. Chagas e Silva 2085 (EFC, FUEL). Cerro Azul, 5.X.1960, fl., G. Hatschbach 7293 (MBM, UPCB). Curitiba, 13.XI.1986, fl., R. Kummrow 2833 (MBM,
UPCB). Piraí do Sul, 15.X.1996, fl., L.H. Soares-Silva 656 (EFC, FUEL). Piraquara, 8.III.1999, fl., A. Lacerda 129 (UPCB). Telêmaco Borba, 23.IX.2008, fl., $M$. Kaehler 296 (UPCB).

Espécie ocorre na Argentina, Paraguai e Brasil, do Rio Grande do Sul a Bahia (Landrum 1986; Sobral et al. 2010). No Paraná, ocorre em floresta ombrófila densa, floresta ombrófila mista, floresta estacional semidecidual e vegetações secundárias. Coletada com flores de outubro a abril, e frutos por quase todo o ano.

Plantas com considerável variação morfológica, principalmente quanto ao tamanho das folhas e flores. Raramente os pedúnculos saem de nós desprovidos de folhas. A espécie é freqüentemente confundida com C. xanthocarpa, diferindo desta por apresentar os lobos do cálice mais largos e curtos.

\section{Campomanesia guazumifolia (Cambess.)} O.Berg, Linnaea 27: 434. $1856 . \quad$ Fig. 2d, e

Arbustos ou árvores 3-10 m alt.; ramos, pecíolos, pedúnculos e todas as nervuras densamente cobertas por tricomas ca. $0,5 \mathrm{~mm}$ compr. Folhas com pecíolo 1,5-12,5 mm compr.; lâmina 4,5-12,5 ×2-6 cm, elíptica, lanceolada ou oval, discolor, não lustrosa, plana, cartácea, raro coriácea, ápice agudo ou menos frequentemente acuminado, base aguda a arredondada, margem inteira, nervuras laterais 8-15 de cada lado, todas as nervuras salientes na face abaxial e impressas ou sulcadas na face adaxial, sem domácias formadas por tufos de tricomas na face abaxial, glândulas ausentes ou esparsas em ambas as faces. Pedúnculos 0,1-0,3 cm compr., unifloros; bractéolas $5-5,1 \times 0,6-0,8 \mathrm{~mm}$, lineares, caducas antes da antese. Flores com hipanto coberto por tricomas; cálice fechado no botão abrindo-se em lobos irregulares cobertos por tricomas em ambas as faces, glândulas ausentes ou presentes externamente; pétalas $11-23 \times 7-20,5 \mathrm{~mm}$, glabras ou com poucos tricomas, glândulas ausentes ou presentes em pequena quantidade; estames 210-670, glândula apical frequentemente presente; ovário 9-12-locular; estilete 7-15 mm compr. Fruto $8-11 \times 9-15 \mathrm{~mm}$, globoso, liso, coberto por tricomas.

Material selecionado: Fênix, 4.XII.1999, fr., M. Borgo 567 (MBM, UPCB). Foz do Iguaçu, 11.X.1976, fl., E. Buttura 106 (MBM). Guapirama, 18.XII.1989, fr., V.P. Oliveira (MBM 138267). Guarapuava, 6.XI.1963, fl., G. Hatschbach 10329 (UPCB). Jaguariaíva, 13.XI.1964, fl., G. Hatschbach 35427 (MBM). Ortigueira, 26.VIII.1997, fl., M.R.C. Paiva (FUEL 21404, UPCB). Porto Rico, 23.III.1989, fl., M.A. Assis (MBM 194261). 
São Jerônimo da Serra, 4.X.1999, fl., O.C. Pavão (FUEL 28290, UPCB). São Mateus do Sul, 30.XI.1986, fl., E. de Melo 63 (MBM, UPCB). Sapopema, 31.X.2000, fr., S.M. Silva 798 (UPCB).

Espécie ocorre do nordeste da Argentina, Paraguai e Brasil, no Rio Grande do Sul a Bahia (Landrum 1986; Sobral et al. 2010). No Paraná, ocorre em floresta ombrófila densa, floresta ombrófila mista, floresta estacional semidecidual e estepe. Coletada com flores entre agosto e dezembro, e frutos entre agosto e fevereiro.

A espécie é caracterizada pelo botão com o cálice completamente fechado, coberto por tricomas, e abrindo-se em lobos irregulares. As nervuras são marcadamente salientes na face abaxial das folhas e cobertas por tricomas, podendo chegar a 15 nervuras laterais de cada lado. O cálice é caduco na frutificação. O tronco descasca em várias camadas finas, aludindo ao nome popular de sete-cascas, ou sete-capotes.

6. Campomanesia neriiflora (O.Berg) Nied., in Engl. \& Prantl., Nat. Pflanzenfam. 3(7):73. 1893.

Fig. 1m-n, $2 \mathrm{f}$

Árvores 3-8 m alt.; ramos, pecíolos e pedúnculos moderadamente cobertos por tricomas 0,1-0,3 mm compr. Folhas com pecíolos 4-11 mm compr.; lâmina 6-15 × 2,5-7 cm, elíptica ou oval, concolor, não lustrosa, plana, membranácea, ápice acuminado, base de atenuada a arredondada, margem inteira, nervuras laterais 7-11 de cada lado, todas as nervuras salientes na face abaxial e impressas na face adaxial, ambas as faces com tricomas presentes nas nervuras, raro na superfície toda ou glabras, face abaxial sempre com domácias formadas por tufos de tricomas nas axilas das nervuras secundárias, glândulas em ambas as faces. Pedúnculos $3-5 \mathrm{~cm}$ compr., unifloros; bractéolas não vistas, caducas antes da antese. Flores com hipanto densamente coberto por tricomas; cálice aberto no botão, com lobos 2,5-6×4-7,5 mm, 0,4-1,3 vezes mais compridos que largos, coberto por tricomas internamente e nas margens, glândulas presentes externamente; pétalas 20-30×18-25 mm, tricomas nas margens, glândulas presentes externamente; estames 300-600, glândula apical presente; ovário 10-13-locular; estilete 11$17 \mathrm{~mm}$ compr. Fruto 10,5-11,5×13-14 mm, globoso, enrugado, com tricomas esparsos.

Material selecionado: Adrianópolis, 9.I.2000, fr., I. Isernhagen 231 (UPCB); 17.X.2005, fl., J. M. Silva 4395 (UPCB). Antonina, 26.X.1972, fl., G. Hatschbach 30558 (MBM). Cerro Azul, 12.XI.1981, fl., G. Hatschbach 44380 (MBM). Doutor Ulysses, 8.XII.1994, fl., G.
Hatschbach 61478 (MBM). Guaraqueçaba, 16.XI.1993, fl., R.X. Lima 143 (MBM, UPCB).

Material adicional: BRASIL. SÃO PAULO: Piracicaba, 1.X.1984, fl., E.L.M. Catharino 144 (MBM).

Ocorre no Brasil, no leste do Paraná e São Paulo (Landrum 1986; Sobral et al. 2010). No Paraná ocorre em floresta ombrófila densa. Coletada com flores de setembro a dezembro, e frutos em janeiro.

Campomanesia neriiflora é caracterizada por ter folhas membranáceas e concolores, flores grandes e vistosas, com pétalas podendo chegar até $3 \mathrm{~cm}$ comp., e pedúnculos bastante longos. Geralmente os lobos do cálice são mais largos que longos, com o ápice arredondado. Vegetativamente pode ser confundida com C. guaviroba, da qual difere principalmente pelos frutos. Seus frutos rugosos são descritos neste trabalho pela primeira vez. O Paraná é limite sul brasileiro da espécie.

7. Campomanesia pubescens (DC.) O.Berg, Linnaea 27(4): 429. $1856 . \quad$ Fig. 2g

Arbustos ou subarbustos 0,5-1,5 m alt.; ramos, pecíolos, pedúnculos e folhas densamente cobertos por tricomas $0,1-0,3 \mathrm{~mm}$ compr. Folhas com pecíolo 1-6,5 mm compr.; lâmina 1-6,5×0,8-2,5 cm, elíptica a lanceolada, raro oboval, discolor, não lustrosa, plana, membranácea a coriácea, ápice acuminado ou agudo, base aguda, margem inteira, nervuras laterais 5-10 pares de cada lado, todas as nervuras salientes na face abaxial e impressas na face adaxial, sem domácias formadas por tufos de tricomas na face abaxial, glândulas esparsas em ambas as faces. Pedúnculos 0,4-2 cm compr., unifloros; bractéolas 2-6×0,3-0,5 mm, linear ou lanceolada, caducas após antese. Flores com hipanto densamente coberto por tricomas; cálice aberto no botão, com lobos 2-5 × 2-4 mm, 0,7-1,2 vezes mais compridos que largos, densamente cobertos por tricomas em ambas as faces, glândulas presentes externamente; pétalas 7-10 × 3-9 cm, glabras ou com tricomas nas margens, glândulas presentes externamente; estames 100-160, glândula apical ausente; ovário 5-8-locular; estilete 3-9 mm compr. Fruto 5-9 ×6-9 mm, globoso, liso, coberto por tricomas.

Material selecionado: Arapoti, 10.X.1968, fl., G. Hatschbach 19960 (MBM). Guarapuava, 21.X.1969, fl., G. Hatschbach 22576 (MBM). Jaguariaíva, 30.IX.1999, fl., A.C. Cervi 6839 (UPCB); 1.XI.1989, fr., A. Dunaiski (UPCB 33961); 21.X.1995, fl., D.J.S. Carrião 39 (UPCB); 11.X.1999, fr., L. von Linsingen 501 (MBM). São Jerônimo da Serra, 21.IX.1995, fl., L.H. Soares-Silva 407 (EFC, FUEL). Sengés, 11.X.1958, fl., G. Hatschbach 5122 (MBM, UPCB). 
Espécie ocorre no Paraguai e no Brasil, do Paraná ao Mato Grosso, Goiás e Bahia (Landrum 1986; Sobral et al. 2010). No Paraná ocorre em savana e pouco frequentemente em estepe. Coletada com flores de agosto a dezembro, e frutos de outubro a março.

A espécie é caracterizada por apresentar indumento denso e folhas marcadamente discolores, tanto frescas quanto em material herborizado. Segundo Landrum (1986), os espécimes do Paraná, diferente de outras regiões, apresentam folhas densamente cobertas por tricomas esbranquiçados pelo menos na face abaxial, o que foi confirmado neste trabalho. As flores aparecem com as folhas ainda muito jovens. Geralmente apresenta xilopódio. O Paraná é limite sul brasileiro da espécie.

\section{Campomanesia reitziana D.Legrand, Sellowia} 8:71. 1957.

Fig. $2 \mathrm{~h}$

Árvores ou arbustos 3-20 m; ramos, pecíolos e pedúnculos esparsamente cobertos por tricomas $0,1-$ $0,3 \mathrm{~mm}$ comp., raro glabros. Folhas com pecíolos $1-$ 9,5 mm compr.; lâmina 4,5-13,5×2-7 cm, elíptica a oblonga, raro oval, discolor ou concolor, não lustrosa, bulada ou raramente plana, cartácea ou coriácea, ápice acuminado, base aguda, arredondada ou cordada, margem denticulada, nervuras laterais 8-12 de cada lado, todas as nervuras salientes na face abaxial e impressas ou sulcadas na face adaxial, ambas as faces com tricomas esparsos nas nervuras, face abaxial sempre com domácias formadas por tufos de tricomas nas axilas das nervuras secundárias, glândulas na face abaxial. Pedúnculos 0,5-4 cm compr., unifloros; bractéolas 4-7,5 ×0,6-2 mm, lineares ou elípticas, caducas após antese. Flores com hipanto coberto por tricomas; cálice aberto no botão, com lobos 3-4×3,5$4,5 \mathrm{~mm}, 0,7-1,1$ vezes mais compridos que largos, tricomas presentes em ambas as faces, glândulas presentes externamente; pétalas 5,5-8 × 5-7 mm, glabras ou com tricomas nas margens, glândulas ausentes ou presentes externamente; estames 100160, glândula apical ausente; ovário 8-13-locular; estilete 4,5-5,5 mm compr. Fruto 4,5-13 ×6-14 mm, globoso, lisos, com tricomas esparsos.

Material selecionado: Antonina, 9.IV.1996, fr., J.M. Silva 1648 (MBM). Piraquara, 11.XII.1981, fl., G. Hatschbach 44475 (MBM).

Material adicional: BRASIL. SANTA CATARINA: Blumenau, 16.X.2000, fl., M. Sobral (MBM 317011). Brusque, 20.VI.1950, fl., R. Klein 222 (UPCB). Florianópolis, 12.X.1971, fr., A. Bresolin 366 (MBM). Piçarras, 17.VII.1969, fr., C. Stellfeld 1720 (UPCB).

Ocorre no Brasil, na região costeira de Santa Catarina a São Paulo (Sobral et al. 2010). No Paraná ocorre em floresta ombrófila densa e floresta ombrófila mista. Coletada com flores em junho, outubro e dezembro, e frutos em abril, julho e outubro.

A espécie é caracterizada pelas folhas, que podem ser buladas ou não, com margens marcadamente denticuladas, base frequentemente cordada, e glândulas visíveis apenas na face abaxial. As bractéolas podem ser persistentes até os frutos e apresentar bordos denticulados.

\section{Campomanesia schlechtendaliana (O.Berg)} Nied., in Engl. \& Prantl. Nat. Pflanzenfam. 3(7): 73. 1893.

Fig. 2i, j

Árvore 5-15 m alt.; ramos, pecíolos e pedúnculos glabros ou esparsamente cobertos por tricomas $0,1-0,3 \mathrm{~mm}$ compr. Folhas com pecíolos 1,56 mm compr.; lâmina 3,5-11×2-5 cm, elíptica ou oval, concolor, lustrosa, plana, coriácea, ápice acuminado a agudo, base obtusa ou arredondada, margem inteira, nervuras laterais 8-13 de cada lado, todas as nervuras salientes na face abaxial e impressas ou sulcadas na face adaxial, ambas as faces glabras ou com tricomas sobre as nervuras, face abaxial sempre com domácias formadas por tufos de tricomas nas axilas das nervuras secundárias, glândulas na face abaxial. Pedúnculos 0,3-0,5 cm compr., unifloros; bractéolas 5,7-6×1,5$2 \mathrm{~mm}$, lineares, caducas antes da antese. Flores com hipanto coberto por tricomas; cálice quase fechado no botão, abrindo-se em lobos irregulares com tricomas em ambas as faces, glândulas ausentes; pétalas 15-18×14-18 mm, tricomas na base ou glabras, glândulas presentes externamente; estames 150-200, glândula apical ausente; ovário 8-9-locular; estilete 11-12 mm compr. Frutos $12-13 \times 14,5-15 \mathrm{~mm}$, globoso ou subgloboso, liso, coberto por tricomas.

Material selecionado: Antonina, 10.XII.1981, fr., G. Hatschbach 44467 (MBM); 9.XII.1981, fr., L.R. Landrum 3993 (MBM). Campina Grande do Sul, 23.XI.1958, fl., G. Hatschbach 5213 (MBM). Piraquara, 18.XI.1951, fl., G. Hatschbach 2633 (MBM).

Ocorre no Brasil, do Paraná a Bahia (Sobral et al. 2010). No Paraná ocorre em floresta ombrófila densa e floresta ombrófila mista. Coletada com flores em outubro e novembro, e frutos em dezembro.

Campomanesia schlechtendaliana apresenta folhas sempre coriáceas, lustrosas em ambas as faces, concolores, com nervuras marcadamente salientes na face abaxial. Os botões apresentam cálice quase fechado, abrindo-se em lobos irregulares. Difere de C. guazumifolia por ter o ápice do botão com uma pequena abertura e tricomas mais curtos. O Paraná é limite sul brasileiro para a espécie. 
10. Campomanesia sessiliflora (O.Berg) Mattos, Loefgrenia 26: 26. $1967 . \quad$ Fig. 2k

Arbustos 0,5-2 m alt.; ramos, pecíolos, pedúnculos e todas as nervuras cobertos por tricomas ca. 0,3 mm compr. Folhas com pecíolo 1,56,5 mm compr.; lâminas 3-7×1-3 cm, elíptica, oboval ou oblonga, discolor, não lustrosa, bulada, coriácea, ápice agudo a arredondado, base aguda, margem inteira, raro repanda, nervuras laterais 5-10 de cada lado, todas as nervuras salientes na face abaxial e impressas ou sulcadas na face adaxial, sem domácias formadas por tufos de tricomas na face abaxial, glândulas na face abaxial. Pedúnculos $0,1-1,5 \mathrm{~cm}$ compr., unifloros ou trifloros; bractéolas 1,5-3×0,9$1 \mathrm{~mm}$, lineares ou lanceoladas, presentes após antese. Flores com hipanto coberto por tricomas; cálice aberto no botão, com lobos 2,5-4,5 × 2-3,5 mm, 0,61,7 vezes mais compridos que largos, cobertos por tricomas em ambas as faces, glândulas presentes externamente ou ausentes; pétalas 4,5-8 $\times 6,5-8 \mathrm{~mm}$, glabras, glândulas presentes externamente; estames 200-350, glândula apical presente ou ausente; ovário 7-10-locular; estilete 5,5-11,5 mm compr. Fruto 3,5$4,5 \times 5-8,5 \mathrm{~mm}$, globoso ou subgloboso, lisos, coberto por tricomas.

Material selecionado: Campo Mourão, 20.XI.2003, fl., M.G. Caxambu 200 (MBM); 8.XII.1966, fl., G. Hatschbach 13261 (MBM); 20.X.1973, fl., G. Hatschbach 32932 (MBM); 17.V.1992, fr., G. Hatschbach 57068 (MBM, UPCB).

Material adicional: BRASIL. MATO GROSSO DO SUL: Amambai, 10.XII.1982, fr., G. Hatschbach 45859 (MBM). Maracaju, 25.X.1988, fl., G. Hatschbach 52621 (MBM, UPCB). PARAGUAI, HERNANDARIAS: 16.VI.1989, fl., A.C. Cervi 2757 (UPCB).

Ocorre no Paraguai e Brasil, do Paraná ao Mato Grosso, Goiás e Bahia (Landrum 1986; Sobral et al. 2010). No Paraná ocorre em áreas de estepe $\mathrm{e}$ savana. Coletada com flores em maio e de outubro a dezembro, e frutos em maio e dezembro.

A espécie é caracterizada pelos pedúnculos curtos, deixando as flores quase sésseis. No botão floral, o cálice cobre quase todo o globo petalífero. No estado, suas folhas têm a face adaxial bulada, e todas as nervuras são inteiramente cobertas por tricomas em ambas as faces. Geralmente é um arbusto xilopodífero. Foi a única espécie vista que apresentou inflorescências em dicásios trifloros. $\mathrm{O}$ Paraná é limite sul brasileiro da espécie.

Landrum (1986) reconheceu três variedades nesta espécie, sendo apenas $C$. sessiliflora var. bullata (Barb. Rodr.) Landrum ocorrente no estado do Paraná. Segundo o autor, esta variedade caracteriza-se pela lâmina bulada, enquanto $C$. sessiliflora var. sessiliflora e C. sessiliflora var. lanuginosa (Barb. Rodr. ex Chodat \& Hassl.) Landrum têm folhas planas.

11. Campomanesia xanthocarpa O.Berg in Mart, Fl. Bras. 14(1):451. 1857.

Fig. 21

Árvores ou arbustos 1-10m; ramos, pecíolos e pedúnculos glabros ou esparsamente cobertos por tricomas $0,1-0,3 \mathrm{~mm}$ compr. Folhas com pecíolo 3,5-15 mm compr.; lâmina 2-10,5×1-5 cm, elíptica, oboval ou oblonga, discolor, não lustrosa, plana, membranácea a coriácea, ápice acuminado a obtuso, base atenuada a obtusa, raro arredondada, margem inteira ou menos frequentemente crenada, nervuras laterais 5-10 de cada lado, todas as nervuras salientes ou impressas na face abaxial e impressas ou sulcadas na face adaxial, ambas as faces com tricomas na superfície ou apenas sobre as nervuras, raro glabras, face abaxial sempre com domácias formadas por tufos de tricomas nas axilas das nervuras secundárias, glândulas em ambas as faces. Pedúnculos (0,7-)1-3,5 cm compr., unifloros; bractéolas 2,5-6 × 0,2-0,5 mm, lineares, caducas antes da antese. Flores com hipanto coberto por tricomas, raro glabro; cálice aberto no botão, com lobos $1,5-5,5 \times 2-5,5 \mathrm{~mm}, 0,7-1,8$ vezes mais compridos que largos, tricomas presentes internamente ou nas margens, glândulas presentes externamente; pétalas 4-9,5(-11) × 2,5-9 mm, glabras ou tricomas nas margens, glândulas presentes externamente; estames 80-150, glândula apical ausente; ovário 5-10-locular; estilete 3-7 mm compr. Fruto (4-)7,5-10×5,5-8,5 mm, globoso, liso, glabro ou com tricomas esparsos.

Material selecionado: Bocaiúva do Sul, 26.XI.1986, fr., G. Hatschbach 50807 (MBM, UPCB). Curitiba, 18.XI.1987, fr., J.M. Silva 410 (MBM, UPCB). Fênix, 18.X.1995, fl., S.B. Mikich (MBM, UPCB 33158). Guarapuava, 12.X.1962, fl., G. Hatschbach 9340 (MBM, UPCB). Londrina, 17.XI.1969, fl., G. Hatschbach 22902 (MBM, UPCB). Mandirituba, 30.XI.1981, fr., L.R. Landrum 3891 (MBM). São Mateus do Sul, 14.X.1986, fl., R.M. Britez 978 (MBM, UPCB). Telêmaco Borba, 9.XI.1995, fl., S.A. Filipaki (UPCB 33158). Tijucas do Sul, 4.XI.1988, fl., R. Kummrow 3084 (MBM, UPCB).

Ocorre no Paraguai, nordeste da Argentina e Brasil, do Rio Grande do Sul a Minas Gerais (Landrum 1986; Sobral et al. 2010). No Paraná ocorre em floresta ombrófila densa, floresta ombrófila mista, floresta estacional semidecidual, estepe e vegetação secundária. Coletada com flores de julho a fevereiro, e frutos de agosto a janeiro. 
A espécie apresenta grande variação morfológica, com folhas de diversos tamanhos e texturas. Mais próximo à costa do estado, os indivíduos apresentam folhas maiores e mais robustas. Vegetativamente pode ser confundida com C. guaviroba, diferindo desta por apresentar os lobos do cálice mais compridos e estreitos. No botão, o cálice pode ocultar parcialmente o globo petalífero.

\section{Agradecimentos}

À equipe do Museu Botânico Municipal (MBM) e aos curadores dos demais herbários, os empréstimos de exsicatas e permissão para consultas. À Diana Carneiro e Rosane Quintella, as ilustrações. O primeiro autor recebe bolsa de Iniciação Científica, e o segundo recebe bolsa produtividade, ambos do CNPq.

\section{Referências}

Govaerts, R.; Sobral, M.; Ashton, P.; Barrie, F.; Holst, B. K.; Landrum, L.R.; Matsumoto, K.; Mazine, F.F.; Nic Lughadha, E; Proença, C.; Soares-Silva, L.H.; Wilson P.G. \& Lucas, E. 2008. World checklist of Myrtaceae. The board of trustees of the Royal Botanic Gardens, Kew. 455p. Disponível em <http:/ /www.kew.org/wcsp/>. Acesso em 22 Dez 2010.

Landrum, L.R. 1982. The development of the fruits and seeds of Campomanesia (Myrtaceae). Brittonia 34: 220-224.

Landrum, L.R. 1986. A monograph of Campomanesia, Pimenta, Blepharocalyx, Legrandia, Acca, Myrrhinium, and Luma (Myrtaceae). Flora Neotropica 45: 1-178.

Landrum, L.R. \& Kawasaki, M.L. 1997. The genera of myrtaceae in Brazil: an illustrated synoptic treatment and identification keys. Brittonia 49: 508-536.

Legrand, C.D. \& Klein, R.M. 1977. Mirtáceas Campomanesia, Feijoa, Britoa, Myrrhinium, Hexachlamys, Siphoneugena, Myrcianthes,
Neomitranthes, Psidium. In: Reitz, P.R. Flora Ilustrada Catarinense. Pp. 1-730.

Legrand, C.D. \& Klein, R.M. 1978. Mirtáceas Myrciaria, Pseudocaryophyllus, Blepharocalyx, espécies suplementares, espécies cultivadas, generalidades. In: Reitz, P.R. Flora Ilustrada Catarinense. Pp 1-876.

Leite, P.F. 1994. As diferentes unidades fitoecológicas da Região Sul do Brasil; proposta de classificação. Dissertação de Mestrado. Universidade Federal do Paraná, Curitiba. 160p.

Lucas, E.J.; Harris, S.A.; Mazine, F.F.; Belsham, S.R.; Nic Lughadha, E.M.; Telford, A.; Gasson, P.E. \& Chase, M. W. 2007. Suprageneric phylogenetics of Myrteae, the generically richest tribe in Myrtaceae (Myrtales). Taxon 56: 1105-1128.

Maack, R. 1968. Geografia física do estado do Paraná. BADEP/UFPR/IBTP, Curitiba. 350p.

McVaugh, R. 1968. The genera os American Myrtaceae: an interim report. Taxon 17: 354-418.

Sobral, M. 2003. A família Myrtaceae no Rio Grande do Sul. Unisinos, São Leopoldo. 215p.

Sobral, M.; Proença, C.; Souza, M.; Mazine, F. \& Lucas, E. 2010. Myrtaceae. In: Forzza, R.C. (org.). Lista de espécies da flora do Brasil. Jardim Botânico do Rio de Janeiro. Disponível em <http://floradobrasil.jbrj. gov.br/2010>. Acesso em 22 Dez 2010.

Thiers, B. 2010 [continuosly updated]. Index Herbariorum: a global directory of public herbaria and associated staff. New York Botanical Garden's Virtual Herbarium. Disponível em <http:// sweetgum.nybg.org/ih>. Acesso em 17 Jan 2010.

Wilson, P. G.; O’Brien, M. M.; Gadek, P. A.. \& Quinn, C. J. 2001. Myrtaceae revisited: A reassessment of infrafamilial groups. American Journal of Botany 88: 2013-2025.

Wilson, P.G.; O’Brien, M.M.; Heslewood, M.M.; Quinn, C.J. 2005. Relationships within Myrtaceae sensu lato based on a matK phylogeny. Plant Systematics and Evolution 251: 3-19. 